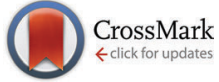

Cite this: J. Mater. Chem. C, 2016, 4, 8930

Received 21st June 2016, Accepted 4th September 2016

DOI: $10.1039 / c 6 t c 02567 f$

www.rsc.org/MaterialsC

\section{Photoluminescence, cathodoluminescence and micro-Raman investigations of monoclinic nanometre-sized $\mathrm{Y}_{2} \mathrm{O}_{3}$ and $\mathrm{Y}_{2} \mathrm{O}_{3}: \mathrm{Eu}^{3+}$}

\author{
Daniel den Engelsen, ${ }^{a}$ Terry G. Ireland ${ }^{* a}$ Paul G. Harris, ${ }^{a}$ George R. Fern, ${ }^{a}$ \\ Paul Reip ${ }^{b}$ and Jack Silver ${ }^{a}$
}

\begin{abstract}
Herein we describe a large scale synthesis of nanosized, monoclinic $\mathrm{Y}_{2} \mathrm{O}_{3}$ and $\mathrm{Y}_{2} \mathrm{O}_{3}$ :Eu ${ }^{3+}$ with 2 mol\% $\mathrm{Eu}^{3+}$ in a plasma-discharge chamber. This high yield synthesis provided nanosized particles with dimensions between $5 \mathrm{~nm}$ to $50 \mathrm{~nm}$, which were stable during shelf life at ambient conditions for more than 6 years. We assume that the Gibbs-Thomson effect is responsible for this unexpected high stability. Annealing at $950{ }^{\circ} \mathrm{C}$ completely transformed the monoclinic particles into the cubic phase, which was indicated by the photo- and cathodoluminescence emission spectra in addition to the much stronger light output. The undoped $\mathrm{Y}_{2} \mathrm{O}_{3}$ material was contaminated with $\mathrm{Dy}^{3+}$, which showed characteristic and rather strong luminescence upon activation with a $\mathrm{He}-\mathrm{Ne}$ laser at $632.8 \mathrm{~nm}$, both at the Stokes and anti-Stokes side. Photoluminescence, cathodoluminescence and Raman spectra of the undoped and doped monoclinic nanocrystals were recorded and partially interpreted.
\end{abstract}

\section{Introduction}

Yttrium oxide $\left(\mathrm{Y}_{2} \mathrm{O}_{3}\right)$ doped with trivalent $\mathrm{Eu}^{3+}$ is a well-known red emitting phosphor, which has found applications in fluorescent lamps and plasma display panels. ${ }^{1,2}$ For application in high resolution displays it was thought that small phosphors particles would be necessary and this assumption increased interest to produce nanometre sized $\mathrm{Y}_{2} \mathrm{O}_{3}: \mathrm{Eu}^{3+}{ }^{3}$ In the industrial applications of $\mathrm{Y}_{2} \mathrm{O}_{3}: \mathrm{Eu}^{3+}$ the $\mathrm{Y}_{2} \mathrm{O}_{3}$ host has the cubic (C type) phase, which is stable at ambient conditions and, most important, it has a rather high luminous efficiency when doped with $\mathrm{Eu}^{3+}$. There are three other $\mathrm{Y}_{2} \mathrm{O}_{3}$ polymorphs, two of these have the A- and B-type rare earth sesquioxide structures that correspond to hexagonal and monoclinic phases respectively. The latter monoclinic B-type phase is formed at high pressure, whilst the hexagonal A-type structure has been reported to be formed at $2325{ }^{\circ} \mathrm{C},{ }^{4}$ which is close to the melting temperature of $\mathrm{Y}_{2} \mathrm{O}_{3}$ at $2410{ }^{\circ} \mathrm{C}$. Finally, the cubic $\mathrm{Y}_{2} \mathrm{O}_{3}$ polymorph transforms to a fluorite phase with disordered oxygen vacancies at $2308{ }^{\circ} \mathrm{C} .{ }^{5}$ In this study we focus on the monoclinic and cubic phases of $\mathrm{Y}_{2} \mathrm{O}_{3}: \mathrm{Eu}^{3+}$, the high temperature phases will not be considered.

\footnotetext{
${ }^{a}$ Centre for Phosphor and Display Materials, Wolfson Centre for Materials Processing, Brunel University London, Uxbridge, Middlesex, UB8 3PH, UK.

E-mail: Terry.ireland@brunel.ac.uk

${ }^{b}$ Intrinsiq Materials Ltd, Building Y25, Cody Technology Park, Ively Road,

Farnborough, Hampshire, GU14 OLX, UK
}

Literature on the synthesis and spectral characterisation of monoclinic $\mathrm{Y}_{2} \mathrm{O}_{3}: \mathrm{Eu}^{3+}$ is rather modest as compared to the vast literature on the cubic structure. The synthesis of monoclinic $\mathrm{Y}_{2} \mathrm{O}_{3}$ at ambient pressure conditions is not obvious; mostly the cubic phase will be obtained upon annealing powders at high temperature. Flame spray pyrolysis has been used to prepare nanometre-sized monoclinic $\mathrm{Y}_{2} \mathrm{O}_{3}$ : $\mathrm{Eu}^{3+}$ or a mixture of the cubic and monoclinic phases. ${ }^{4-6-10}$ By adjusting the residence time of the particles in the flame, Camenzind et al. ${ }^{6}$ were able to determine the structure of the particles. Short residence times yielded small particle size with predominantly monoclinic structure. Qin et al. synthesised only monoclinic material when varying the residence time of the precursor in the flame. ${ }^{7}$ Monoclinic $\mathrm{Y}_{2} \mathrm{O}_{3}$ : $\mathrm{Eu}^{3+}$ nanometre-sized particles with approximately $10 \mathrm{~nm}$ in diameter were reported via different gas condensation methods. ${ }^{11,12}$ Wang et al. ${ }^{13}$ studied phase transitions in $\mathrm{Y}_{2} \mathrm{O}_{3}$ and $\mathrm{Y}_{2} \mathrm{O}_{3}: \mathrm{Eu}^{3+}$ as a function of pressure. Compression of cubic $\mathrm{Y}_{2} \mathrm{O}_{3}: \mathrm{Eu}^{3+}$ at room temperature and medium pressure yielded the monoclinic phase, which finally transformed into the hexagonal phase at very high pressure. Decompression produced the monoclinic phase only. Similar results for $\mathrm{Y}_{2} \mathrm{O}_{3}$ : $\mathrm{Eu}^{3+}$ were found by Zhang et al. ${ }^{14}$ by recording the photoluminescence as a function of pressure. From these works it can be concluded that once the monoclinic phase has been formed, it does not automatically return to the cubic phase. A plasma coating process for the fabrication of monoclinic undoped $\mathrm{Y}_{2} \mathrm{O}_{3}$ thin films was described by Gourlaouen et al. ${ }^{15}$ These authors indicated that starting from cubic $\mathrm{Y}_{2} \mathrm{O}_{3}$ powder the yield of monoclinic $\mathrm{Y}_{2} \mathrm{O}_{3}$ was 
about $5 \%$ at a maximum. They also described the phase transition of monoclinic $\mathrm{Y}_{2} \mathrm{O}_{3}$ to cubic $\mathrm{Y}_{2} \mathrm{O}_{3}$ by annealing at high temperatures. The stability of the monoclinic phase of $\mathrm{Y}_{2} \mathrm{O}_{3}$ at room temperature and ambient pressure has been explained in terms of the Gibbs-Thomson effect, ${ }^{4,11,16}$ which indicates that a very high specific surface area of the nano-particles increases the internal pressure to the same order of magnitude as that of the pressure required for the cubic-monoclinic transformation.

There are a number of problems encountered with the flame spray pyrolysis and gas condensation methods to produce $\mathrm{Y}_{2} \mathrm{O}_{3}: \mathrm{Eu}^{3+}$ nano-particles. First, the yields are usually low. Second, the resulting material in some cases is $\mathrm{Y}_{2} \mathrm{O}_{3}: \mathrm{Eu}^{3+}$ precursor that requires heat treatment to convert to the luminescent oxide: as a consequence this will cause particle growth and sintering between particles. Finally, in most cases mixtures of the monoclinic and cubic phases are obtained. Monoclinic bulk $\mathrm{Y}_{2} \mathrm{O}_{3}$ is not stable at ambient pressure, whereas nanometresized particles seem to be stable. This raises the questions (1) what would be the critical size to obtain stability and (2) what happens in a powder of monoclinic $\mathrm{Y}_{2} \mathrm{O}_{3}$ (doped or non-doped) with a grain size distribution from micrometres to nanometres? These two latter questions were also important in starting this study. Here we describe the synthesis of discrete nanometre sized-particles of $\mathrm{Y}_{2} \mathrm{O}_{3}$ and $\mathrm{Y}_{2} \mathrm{O}_{3}: \mathrm{Eu}^{3+}$ using a high-temperature plasma method that provides a high product yield. The original idea in choosing this method was to make nanometre-sized cubic $\mathrm{Y}_{2} \mathrm{O}_{3}$ doped with rare earth elements on a large scale. As it turned out in the course of this work, this synthesis provided primarily the monoclinic phase of $\mathrm{Y}_{2} \mathrm{O}_{3}$, which was quite unexpected. The materials were characterised using X-ray powder diffraction (XRD) and transmission electron microscopy (TEM), both in stationary and scanning modes. In the case of $\mathrm{Y}_{2} \mathrm{O}_{3}: \mathrm{Eu}^{3+}$, cathodoluminescence imaging was carried out and the photoluminescence (PL), cathodoluminescence (CL) and Raman scattering properties were also studied.

\section{Materials and methods}

\subsection{Materials}

Starting materials, $\mathrm{Y}_{2} \mathrm{O}_{3}$ powder and europium oxide (Absco Ltd, Haverhill, UK, 99.99\%) were used without additional purification. The monoclinic $\mathrm{Y}_{2} \mathrm{O}_{3}$ and $\mathrm{Y}_{2} \mathrm{O}_{3}: \mathrm{Eu}^{3+}$ materials were produced according to Intrinsiq's patented plasma process ${ }^{17}$ by wet mixing europium oxide and cubic yttrium oxide in a tubular mixer, followed by drying and then a secondary crushing process to break the materials down to sub $10 \mu \mathrm{m}$. This feedstock of precursors was fed by gravity into the hot plasma $\left(>9000{ }^{\circ} \mathrm{C}\right)$, in which it vaporised and condensed to form the nanometresized phosphor particles.

Typical parameters for producing about $1 \mathrm{~kg}$ of material were $80 \mathrm{~kW}$ torch power, with $2000 \mathrm{l} \mathrm{min}^{-1}$ argon flow rate to cool the materials down to suitable temperature for quality testing and collection on a set of nano-porous stainless steel filters, before blowing back to release and collect.
Cubic nanometre-sized $\mathrm{Y}_{2} \mathrm{O}_{3}: \mathrm{Eu}^{3+}$, which was measured for reference purposes only, was synthesized according to the urea precipitation method, which has been described in detail in our previous work. ${ }^{18-20}$

\subsection{Methods and equipment}

XRD measurements were made using a Bruker D8 powder diffractometer fitted with a Lynxeye multi-element detector and operating in the theta-theta scan mode. The powders were placed in an A100B3B Air tight XRD holder and the data were recorded from $5^{\circ}<2 \theta<100^{\circ}$ at $293 \mathrm{~K}$. Copper radiation was used and the emission profile calibrated using NIST 660a $\mathrm{LaB}_{6}$ line profile standard and line position was calibrated using a corundum standard from Bruker. The line profile was analysed with Bruker Diffrac Plus Evaluation version 13,0,0,2 and the data were refined using Bruker's AXS Topas version 3.0 Rietveld refinement computer software. The background was fitted with a Chebychev polynomial.

For the studies in the TEM copper grids coated with thin carbon films having small holes (holey carbon films) were used as substrates: these are transparent to the high-energy electrons. TEM was carried out using a JEOL 2100F (Japan). The TEM was equipped with a Vulcan ${ }^{\mathrm{TM}}$ CL detector of Gatan (USA) for imaging and spectroscopic purposes. This system used a Czerny-Turner spectrometer with back-illuminated CCD and a grating with 1200 lines per $\mathrm{mm}$ (blazed at $500 \mathrm{~nm}$ ) for collection of $\mathrm{CL}$ emission spectra. Light was collected from the sample using a mirror above and below the sample, which enabled a solid angle of about $5 \mathrm{sr}$, which is almost half of a sphere.

For recording CL spectra samples were mounted in two different high vacuum chambers at a vacuum level of $\approx 3 \times 10^{-6} \mathrm{mbar}$ using Kimball Physics Inc. (USA) electron guns and associated power supplies over the ranges of electron beam voltages of 1-5 kV and 3-15 kV respectively. The electron guns had the ability to focus and defocus the beam over a range of current densities. The luminous efficiency and energy efficiency were measured with a uniform electron beam (by defocusing) at current densities between 1 and $10 \mu \mathrm{A} \mathrm{cm}^{-2}$. Deflection plates enabled optimum positioning of the electron beam on the sample and a $\mathrm{ZnO}: \mathrm{Zn}$ reference. The latter being a non-charging thin film of $\mathrm{ZnO}: \mathrm{Zn}$ powder on ITO to adjust the current in the thin powder layers of $\mathrm{Y}_{2} \mathrm{O}_{3}$ and $\mathrm{Y}_{2} \mathrm{O}_{3}: \mathrm{Eu}^{3+}$ : in this way we could cope with the effect of charging of the non-conductive $\mathrm{Y}_{2} \mathrm{O}_{3}$ layers as explained in our previous work. ${ }^{20}$

Radiance and luminance of CL were measured with a Jeti Radiometer (Spectrobos 1200, Germany) between 380 and $780 \mathrm{~nm}$ as described earlier. ${ }^{18,20} \mathrm{PL}$ - and CL-spectra were measured with a Bentham Instruments dual monochromator system equipped with $0.37 \mathrm{~mm}$ slits. Emission spectra were recorded in the range of $300 \mathrm{~nm}$ to $800 \mathrm{~nm}$ in steps of $0.2 \mathrm{~nm}$. The wavelength error of the Bentham spectrometer was estimated to be $\pm 0.5 \mathrm{~nm}$. Raman and laser induced fluorescence spectra of the samples were measured with a Horiba Jobin Yvon Labram HR monochromator by excitation with a He-Ne laser at 298 K. The wavelength error of the Labram monochromator was smaller: about $\pm 0.2 \mathrm{~nm}$. 


\section{Results}

The nanometre-sized particles of $\mathrm{Y}_{2} \mathrm{O}_{3}$ and $\mathrm{Y}_{2} \mathrm{O}_{3}$ : $\mathrm{Eu}^{3+}$ obtained by high-temperature plasma synthesis were white under the D50 lamp, similar to that of the bulk material; using $254 \mathrm{~nm}$ light excitation only the europium-doped material displayed red luminescence. Energy dispersive X-ray analysis (EDX) of the undoped and doped samples showed some contamination $(<0.5 \%)$ of $\mathrm{Fe}$ and $\mathrm{Cu}$, the $\mathrm{Fe}$ was probably from the stainless steel rings in the reaction chamber and the origin of the $\mathrm{Cu}$ was from the nozzles of the plasma discharge flame. The $\mathrm{Eu}^{3+}$ concentration of the doped sample was about $2 \%$. No other contaminations could be detected with this technique.

Fig. 1 shows the $\mathrm{XRD}$ diagrams of the high-temperature plasma synthesised $\mathrm{Y}_{2} \mathrm{O}_{3}$ and $\mathrm{Y}_{2} \mathrm{O}_{3}$ : $\mathrm{Eu}^{3+}$ nano-particles. They were both predominantly composed of the monoclinic (B-type) phase (89\% and 93\%) with some cubic (C-type) phase (11\% and 7\%) when compared to a reference pattern. This composition of the samples was calculated from the XRD graphs using Bruker's AXS Topas version 3.0 Rietveld refinement computer software. The yield of monoclinic phase was much higher than that obtained by Gourlaouen $e t a l^{15}$ with a plasma spray gun.

The undoped and doped compounds had similar crystallite sizes of $17.7 \mathrm{~nm}$ and $17.9 \mathrm{~nm}$ for the monoclinic phase and $30.0 \mathrm{~nm}$ and $45.0 \mathrm{~nm}$ for the cubic phase, determined by XRD line-broadening analysis using Scherrer's method, which is included in the Topas software.

The TEM image in Fig. 2a represents the as-synthesised monoclinic $\mathrm{Y}_{2} \mathrm{O}_{3}$ nano-particles, which have sizes from $5 \mathrm{~nm}$ to $50 \mathrm{~nm}$. This agrees with the crystallite size as determined from the XRD diagrams. Fig. 2a shows that these particles were sintered and formed a large cluster. Since the image of the $\mathrm{Y}_{2} \mathrm{O}_{3}: \mathrm{Eu}^{3+}$ particles is essentially identical to that of the undoped particles, it will not be reproduced here. The Scanning TEM (STEM) images shown in Fig. $2 \mathrm{~b}$ and $\mathrm{c}$ are at a smaller magnification. Recording of the

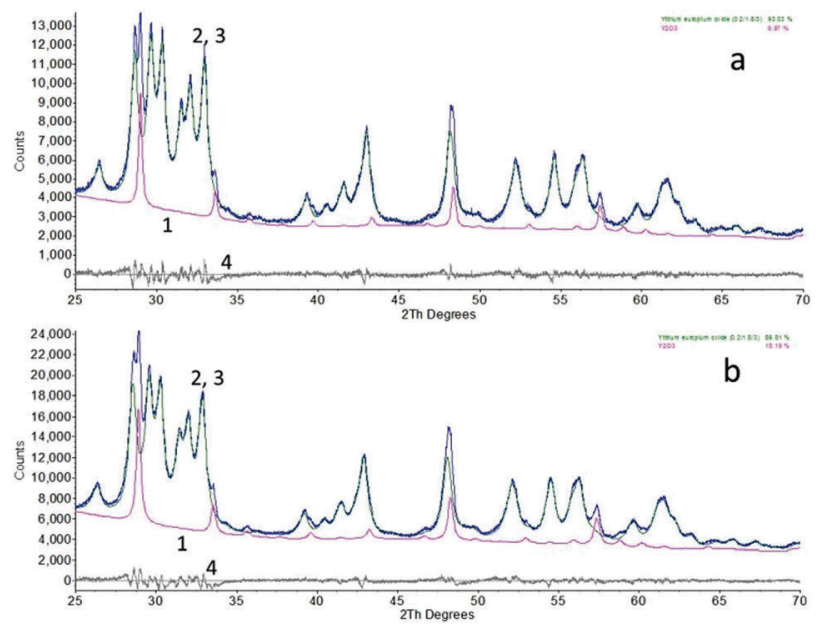

Fig. 1 XRD patterns of $\mathrm{Y}_{2} \mathrm{O}_{3}: \mathrm{Eu}^{3+}$ (a) and undoped $\mathrm{Y}_{2} \mathrm{O}_{3}$ (b) hightemperature plasma synthesised nano-particles. Spectra 1: cubic phase, spectra 2, 3: raw data and fitted XRD-diagrams; 4: difference between spectra 2 and 3 .

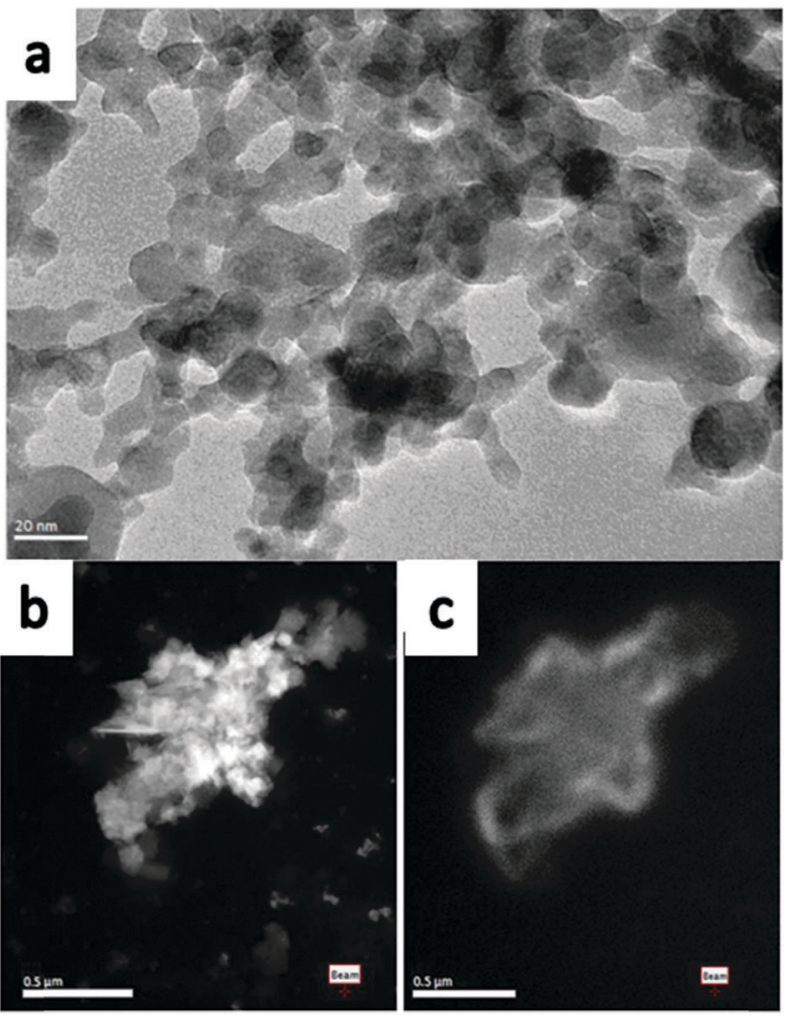

Fig. 2 TEM image of monoclinic (a) $\mathrm{Y}_{2} \mathrm{O}_{3}$ nano-particles, (b) STEM image of monoclinic $\mathrm{Y}_{2} \mathrm{O}_{3}: \mathrm{Eu}^{3+}$ recorded at $200 \mathrm{keV}-170{ }^{\circ} \mathrm{C}$, (c) panchromatic $\mathrm{CL}$ image of particles shown in (b) recorded at same conditions.

panchromatic image (Fig. 2c) was possible by maximizing the current in the e-beam.

Some larger particles of about $250 \mathrm{~nm}$ were observed to be present in the products due to precursor oxides passing directly through the plasma without totally evaporating to ions, presumably due to being too large initially as shown in Fig. 3a. This figure is a STEM image at $200 \mathrm{kV}$ and temperature of $-170{ }^{\circ} \mathrm{C}$ of doped monoclinic material. Since the large particles differ substantially from the smaller monoclinic-phase particles shown in Fig. 2a, we conclude that these particles are non-reacted cubic $\mathrm{Y}_{2} \mathrm{O}_{3}$ precursor material. A proof of this hypothesis is shown in Fig. $3 \mathrm{~b}$, which is the CL spectrum of the large particle, indicated with the red arrow in Fig. 3a, recorded with the Gatan spectrometer connected to the TEM. This spectrum shows only the intrinsic blue emission of cubic $\mathrm{Y}_{2} \mathrm{O}_{3}$ between 400 and $500 \mathrm{~nm}$ upon excitation with high energetic electrons. ${ }^{21}$ From this spectrum it can be concluded that the large spherical particle did not contain the Eu-dopant; routinely a strong $\mathrm{Eu}^{3+}$ emission would be observed from this sized particle. Another indication that this particle must be cubic $\mathrm{Y}_{2} \mathrm{O}_{3}$ is the fact that $2 \% \mathrm{Eu}^{3+}$ will almost quench the intrinsic $\mathrm{Y}_{2} \mathrm{O}_{3}$ emission. ${ }^{21}$ The mere presence of this intrinsic emission is thus a proof that the particle is undoped $\mathrm{Y}_{2} \mathrm{O}_{3}$ precursor. The evidence presented in Fig. 3a and $\mathrm{b}$ indicates that the composition of the synthesized samples calculated above from the XRD-data is somewhat misleading, because the samples contained a small quantity of non-reacted cubic $\mathrm{Y}_{2} \mathrm{O}_{3}$ particles. Since these precursor particles did not 


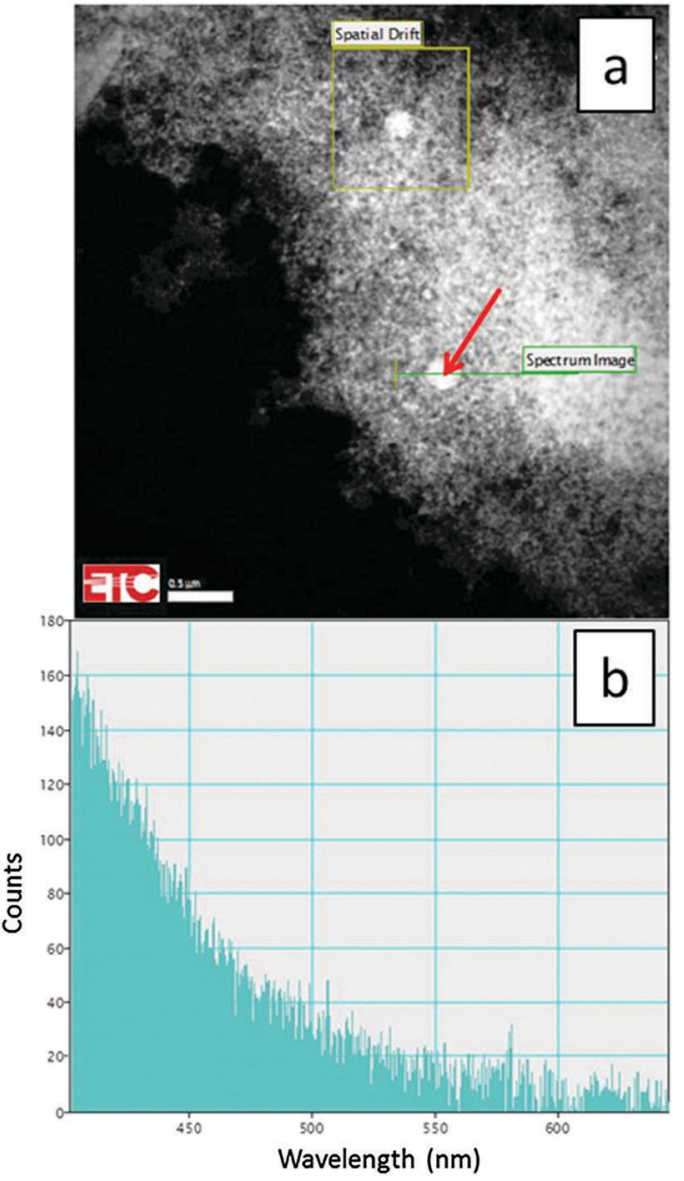

Fig. 3 STEM image (a) of monoclinic $\mathrm{Y}_{2} \mathrm{O}_{3}: \mathrm{Eu}^{3+}$ sample at $200 \mathrm{keV}$ and $-170{ }^{\circ} \mathrm{C}$ with large non-reacted cubic $\mathrm{Y}_{2} \mathrm{O}_{3}$ particles (one indicated by red arrow). CL spectrum (b) of large cubic particle recorded at same conditions with Gatan spectrometer between 400 and $650 \mathrm{~nm}$.

contain $\mathrm{Eu}^{3+}$, the percentage of monoclinic $\mathrm{Y}_{2} \mathrm{O}_{3}: \mathrm{Eu}^{3+}$ is substantially larger than $93 \%$ as compared to cubic $\mathrm{Y}_{2} \mathrm{O}_{3}: \mathrm{Eu}^{3+}$. In the discussion of Fig. 12a hereafter, we shall indicate that the percentage of monoclinic $\mathrm{Y}_{2} \mathrm{O}_{3}: \mathrm{Eu}^{3+}$ is more than $99 \%$ as compared to cubic $\mathrm{Y}_{2} \mathrm{O}_{3}: \mathrm{Eu}^{3+}$ when the quantity of non-reacted precursor material is ignored.

In Fig. 4 XRD diagrams of annealed monoclinic $\mathrm{Y}_{2} \mathrm{O}_{3}: \mathrm{Eu}^{3+}$ nanoparticles over the temperature range $800{ }^{\circ} \mathrm{C}$ to $1000{ }^{\circ} \mathrm{C}$ for 60 minutes are presented. From these diffractograms the transformation from monoclinic to cubic phase is shown to be partial at $900{ }^{\circ} \mathrm{C}$ and complete at $1000{ }^{\circ} \mathrm{C}$. This agrees with the differential scanning calorimetry data published by Zhang $e t ~ a l .{ }^{4}$ that indicates a phase transition from monoclinic to cubic $\mathrm{Y}_{2} \mathrm{O}_{3}$ between $850{ }^{\circ} \mathrm{C}$ and $950{ }^{\circ} \mathrm{C}$. As a consequence of the annealing treatments, an increase in crystallite size was observed: at $800{ }^{\circ} \mathrm{C}$ the crystallite size was $25.6 \mathrm{~nm}$ and $34.3 \mathrm{~nm}$, increasing to $48.5 \mathrm{~nm}$ and $42.7 \mathrm{~nm}$ at $900{ }^{\circ} \mathrm{C}$ for the monoclinic and cubic phases respectively and $63.3 \mathrm{~nm}$ at $1000{ }^{\circ} \mathrm{C}$ for the cubic phase.

The TEM images shown in Fig. $5 \mathrm{a}-\mathrm{c}$ refer to monoclinic $\mathrm{Y}_{2} \mathrm{O}_{3}: \mathrm{Eu}^{3+}$ samples annealed at $800{ }^{\circ} \mathrm{C}, 900{ }^{\circ} \mathrm{C}$ and $1000{ }^{\circ} \mathrm{C}$ for 60 minutes. It can be seen that particle growth occurs with an

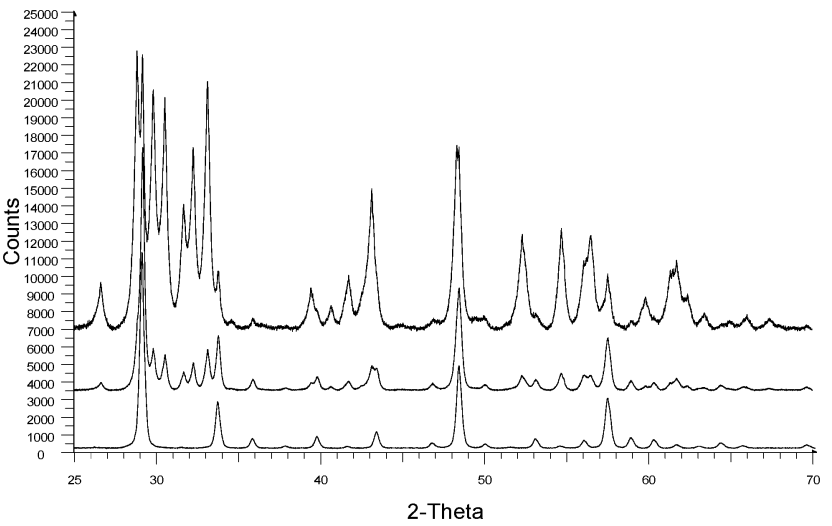

Fig. 4 XRD patterns of monoclinic $\mathrm{Y}_{2} \mathrm{O}_{3}: \mathrm{Eu}^{3+}$ plasma discharge nanoparticles after annealing at $800{ }^{\circ} \mathrm{C}$ (top), $900{ }^{\circ} \mathrm{C}$ (middle) and $1000{ }^{\circ} \mathrm{C}$ (bottom) for 60 minutes.

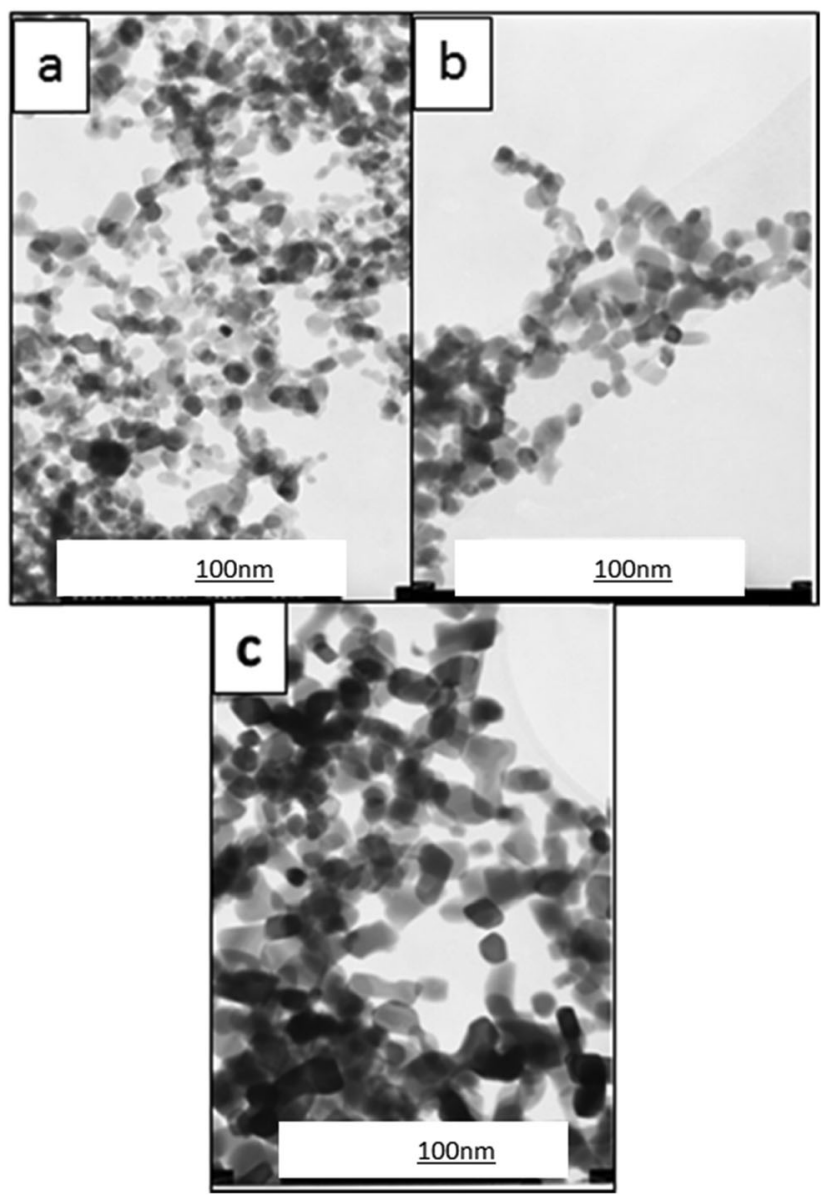

Fig. 5 TEM images of $\mathrm{Y}_{2} \mathrm{O}_{3}: \mathrm{Eu}^{3+}$ samples annealed at (a) $800{ }^{\circ} \mathrm{C}$ (b) $900{ }^{\circ} \mathrm{C}$ and (c) $1000{ }^{\circ} \mathrm{C}$ for 60 minutes.

increase in annealing temperature. After annealing above the monoclinic to cubic phase transition temperature, which occurs between $850{ }^{\circ} \mathrm{C}$ to $950{ }^{\circ} \mathrm{C}$, the particles are observed to grow considerably in size to between $25 \mathrm{~nm}$ to $100 \mathrm{~nm}$.

The normalised PL excitation and emission spectra of the high-temperature plasma synthesised $\mathrm{Y}_{2} \mathrm{O}_{3}: \mathrm{Eu}^{3+}$ nano-particles 


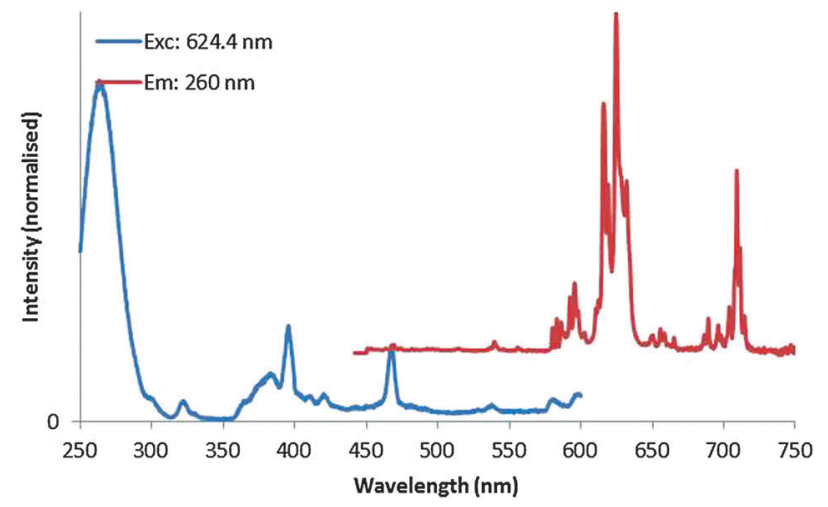

Fig. 6 Normalised PL excitation (monitored at $624 \mathrm{~nm}$, normalised at $260 \mathrm{~nm}$ ) and emission (excited at $260 \mathrm{~nm}$, normalised at $624 \mathrm{~nm}$ ) spectra of monoclinic $\mathrm{Y}_{2} \mathrm{O}_{3}: \mathrm{Eu}^{3+}$ nano-particles.

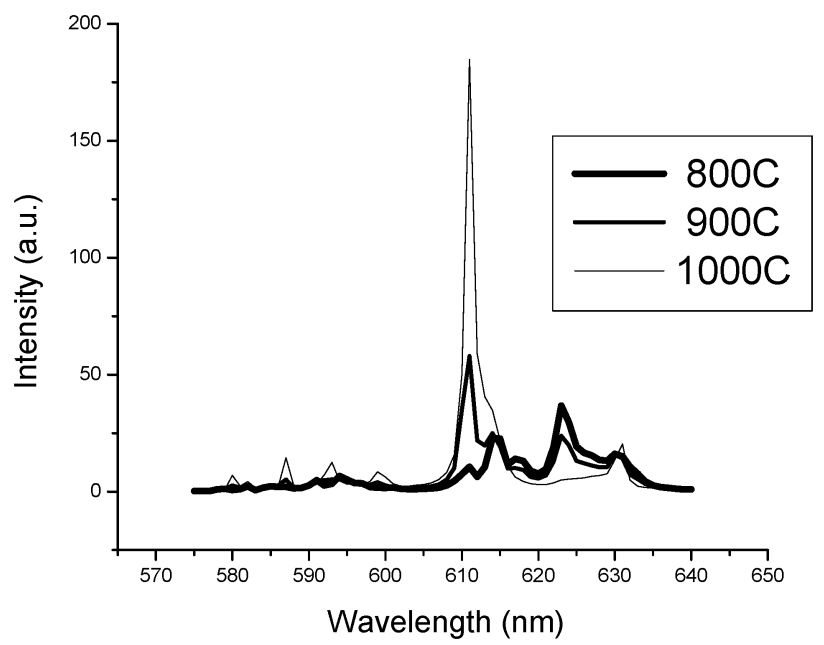

Fig. 7 PL emission spectra (excitation wavelength $254 \mathrm{~nm}$ ) of the plasma discharge process monoclinic $\mathrm{Y}_{2} \mathrm{O}_{3}: \mathrm{Eu}^{3+}$ nano-particles after annealing at $800{ }^{\circ} \mathrm{C}, 900{ }^{\circ} \mathrm{C}$ and $1000{ }^{\circ} \mathrm{C}$ for 60 minutes illustrating the phase transition from monoclinic to cubic.

are presented in Fig. 6. The sample was excited using $260 \mathrm{~nm}$ UV-light; the excitation spectrum was collected monitoring the $624 \mathrm{~nm}$ peak. The emission spectrum is representative of the $\mathrm{Eu}^{3+}$ ion in a monoclinic $\mathrm{Y}_{2} \mathrm{O}_{3}$ host lattice.

A comparison of various PL emission spectra is presented in Fig. 7 for the high-temperature plasma synthesised monoclinic $\mathrm{Y}_{2} \mathrm{O}_{3}: \mathrm{Eu}^{3+}$ nano-particles after annealing for a period of 60 minutes at temperatures of $800{ }^{\circ} \mathrm{C}, 900{ }^{\circ} \mathrm{C}$ and $1000{ }^{\circ} \mathrm{C}$. These spectra illustrate the transition from monoclinic to cubic phase that occurs between $850{ }^{\circ} \mathrm{C}$ and $950{ }^{\circ} \mathrm{C}$ : these spectra agree favourably with the results represented in Fig. 4 . The intensity of light emitted under PL excitation from monoclinic $\mathrm{Y}_{2} \mathrm{O}_{3}: \mathrm{Eu}^{3+}$ phosphor is much weaker than that from a cubic $\mathrm{Y}_{2} \mathrm{O}_{3}: \mathrm{Eu}^{3+}$ phosphor; this is demonstrated by the relative intensities of the spectra shown in Fig. 7 for identical phosphor screen weights and in Fig. 10, to be discussed hereafter.

Fig. 8 shows the PL and CL spectra of monoclinic $\mathrm{Y}_{2} \mathrm{O}_{3}: \mathrm{Eu}^{3+}$. The PL spectrum was obtained by exciting with $260 \mathrm{~nm}$

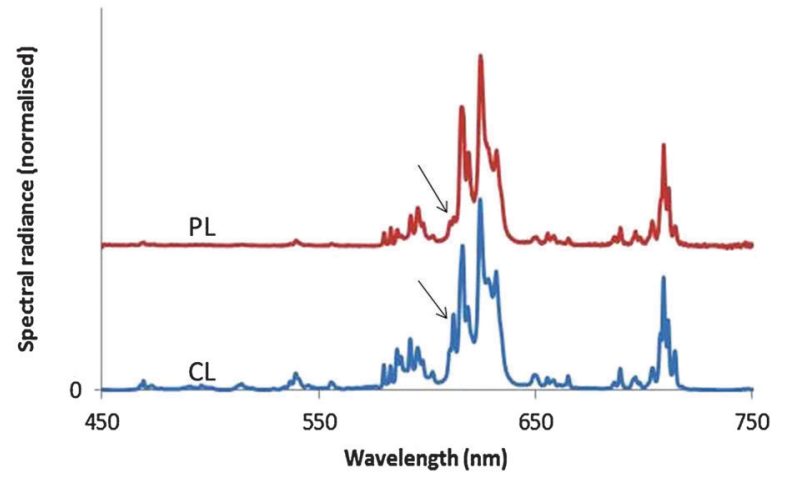

Fig. $8 \mathrm{Cl}$ spectrum (bottom) and PL spectrum (top) of nanosized monoclinic $\mathrm{Y}_{2} \mathrm{O}_{3}: \mathrm{Eu}^{3+}$. The $\mathrm{CL}$ spectrum was recorded at $15 \mathrm{keV}$ beam energy and current density of $1 \mu \mathrm{A} \mathrm{cm}{ }^{-2}$. Both spectra have been normalised to unity at $624 \mathrm{~nm}$, the strongest peak of the ${ }^{5} \mathrm{D}_{0} \rightarrow{ }^{7} \mathrm{~F}_{2}$ transition manifold of monoclinic $\mathrm{Y}_{2} \mathrm{O}_{3}: \mathrm{Eu}^{3+}$. The arrows indicate the ${ }^{5} \mathrm{D}_{0} \rightarrow{ }^{7} \mathrm{~F}_{2}$ transition of cubic $\mathrm{Y}_{2} \mathrm{O}_{3}: \mathrm{Eu}^{3+}$ at $611 \mathrm{~nm}$, which is the only transition of the cubic phase that can be distinguished in these spectra.

ultraviolet light. The CL spectrum refers to a sample that was bombarded with $15 \mathrm{keV}$ electrons; the current density was $1 \mu \mathrm{A} \mathrm{cm}^{-2}$. The further the emission lines in the CL spectrum are from the strong peak at $624 \mathrm{~nm}$, the stronger they are as compared to the corresponding lines in the PL spectrum. The strong ${ }^{5} \mathrm{D}_{0} \rightarrow{ }^{7} \mathrm{~F}_{2}$ line of the cubic phase is the only transition of this material that can be observed in the spectra of Fig. 8. It has been indicated with an arrow. This transition is more clearly visible in Fig. 12a. In Fig. 9 we have depicted the CL spectra of nanosized cubic and monoclinic $\mathrm{Y}_{2} \mathrm{O}_{3}: \mathrm{Eu}^{3+}$. Both spectra were recorded at identical conditions: beam energy of $15 \mathrm{keV}$ and current density of $1 \mu \mathrm{A} \mathrm{cm}{ }^{-2}$.

The assignments of the transition manifolds that are clearly noticeable have been indicated in Fig. 9. The wavelength difference of corresponding transition clusters between monoclinic and cubic $\mathrm{Y}_{2} \mathrm{O}_{3}: \mathrm{Eu}^{3+}$ is small, which is to be expected for intra-4f transitions of the $\mathrm{Eu}^{3+}$ ion. The table in Fig. 9 lists the lowest energy levels (in $\mathrm{cm}^{-1}$ ) for the indicated electronic states of $\mathrm{Eu}^{3+}$ in the two hosts. The levels for monoclinic $\mathrm{Y}_{2} \mathrm{O}_{3}: \mathrm{Eu}^{3+}$

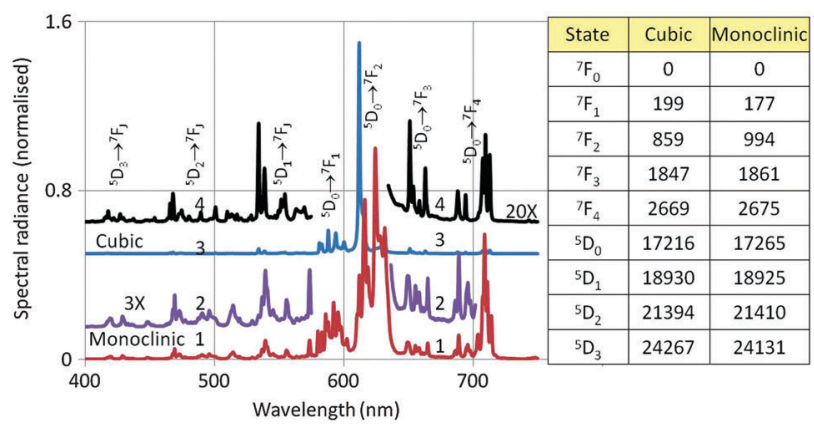

Fig. 9 Comparison of $\mathrm{CL}$ spectra of cubic and monoclinic $\mathrm{Y}_{2} \mathrm{O}_{3}: \mathrm{Eu}^{3+}$. Spectra (1) and (2) refer to monoclinic $\mathrm{Y}_{2} \mathrm{O}_{3}: \mathrm{Eu}^{3+}$, while spectra (3) and (4) refer to cubic $\mathrm{Y}_{2} \mathrm{O}_{3}: \mathrm{Eu}^{3+}$. Spectrum (2) is three times vertically magnified from (1) while (4) is twenty times magnified from (3). In the table the lowest energy levels (in $\mathrm{cm}^{-1}$ ) of some ${ }^{7} \mathrm{~F}_{\mathrm{J}}$ and ${ }^{5} \mathrm{D}_{\mathrm{J}}$ electronic states of $\mathrm{Eu}^{3+}$ in cubic and monoclinic $\mathrm{Y}_{2} \mathrm{O}_{3}$ are compared. 
have been calculated from the spectra represented in Fig. 9, while the levels for the cubic phase are from Wen et al. ${ }^{22}$ and Gruber et $a .^{23}$ The largest difference between the cubic and monoclinic material was found for the level of ${ }^{7} \mathrm{~F}_{2}$ : for the other states the levels are quite similar. In spite of the similarity in energy, the spectra of the cubic and monoclinic phase look quite different, especially for the ${ }^{5} \mathrm{D}_{0} \rightarrow{ }^{7} \mathrm{~F}_{2}$ transition manifold. In cubic $\mathrm{Y}_{2} \mathrm{O}_{3}: \mathrm{Eu}^{3+}$ the peak with the strongest spectral radiance has the lowest wavelength $(611 \mathrm{~nm})$, while in monoclinic $\mathrm{Y}_{2} \mathrm{O}_{3}: \mathrm{Eu}^{3+}$ the peak with the strongest spectral radiance is at $624 \mathrm{~nm}$, which is the 5th peak of the ${ }^{5} \mathrm{D}_{0} \rightarrow{ }^{7} \mathrm{~F}_{2}$ manifold: this can be observed more clearly in Fig. 12a, to be discussed later. The differences in spectral radiance between the peaks of a particular transition manifold exemplify the sensitivity of $\mathrm{Eu}^{3+}$ to the coordination: in the cubic material $\mathrm{Eu}^{3+}$ is 6-fold coordinated, whereas in monoclinic $\mathrm{Y}_{2} \mathrm{O}_{3}$ it is 7 -fold coordinated. ${ }^{12}$

The spectra of monoclinic $\mathrm{Y}_{2} \mathrm{O}_{3}: \mathrm{Eu}^{3+}$ synthesised by plasma discharge in Fig. 8 and 9 show the ${ }^{5} \mathrm{D}_{0} \rightarrow{ }^{7} \mathrm{~F}_{2}$ transition of the cubic material at $611 \mathrm{~nm}$, which is substantially larger in the CL spectrum than in the PL spectrum. This is a spectroscopic confirmation of the XRD-results that the high-temperature plasma $\mathrm{Y}_{2} \mathrm{O}_{3}: \mathrm{Eu}^{3+}$ was not purely monoclinic. The first PL spectrum of the monoclinic sample was recorded in 2009 and the most recent in May 2015. Since there was no change in the height of this $611 \mathrm{~nm}$ peak with respect to the heights of neighbouring peaks, it can be concluded that the nanosized monoclinic $\mathrm{Y}_{2} \mathrm{O}_{3}: \mathrm{Eu}^{3+}$ crystals with the rather small particles are stable during shelf life at ambient conditions for a long time.

Luminance and radiance of the samples were measured with the Jeti Radiometer upon electron bombardment between 5 and $15 \mathrm{kV}$ and current density between 1 and $3 \mu \mathrm{A} \mathrm{cm}^{-2}$. From the luminance the luminous efficacy can be calculated, while the energy efficiency is calculated from the measured radiance. ${ }^{18}$ Luminous efficacy results are presented in Fig. 10 for CL measurements at electron beam energies between 1 and $15 \mathrm{keV}$. The curve of the luminous efficacy versus beam voltage does not vary strongly between 5 and $15 \mathrm{kV}$, indicating that at low beam voltages monoclinic $\mathrm{Y}_{2} \mathrm{O}_{3}: \mathrm{Eu}^{3+}$ is already luminescing quite well. However, its luminous efficacy is about 25 times weaker

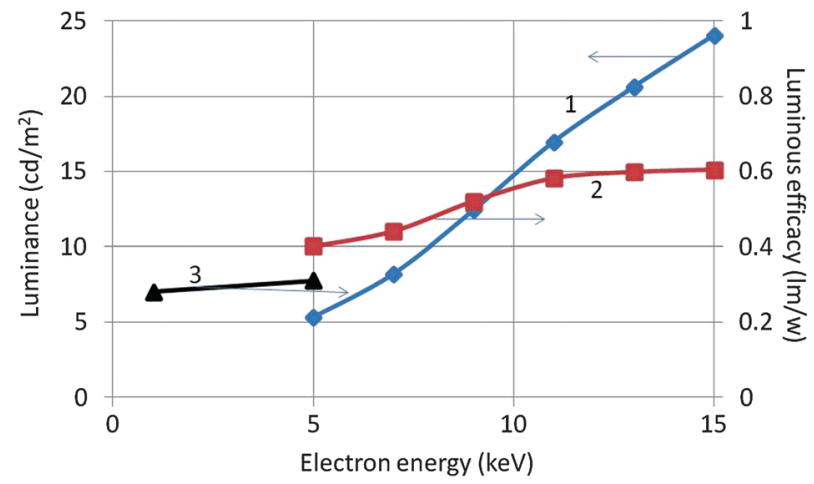

Fig. 10 Luminance (curve 1) and luminous efficacy (curve 2 and line 3) of nanosized monoclinic $\mathrm{Y}_{2} \mathrm{O}_{3}: \mathrm{Eu}^{3+}$ versus energy of the electron beam. Current density was $1 \mu \mathrm{A} \mathrm{cm}{ }^{-2}$. Substrate for the sample of (3) was: Al, substrate for the sample (2) was indium-tin (10\%) oxide (ITO). at $15 \mathrm{kV}$ than that of nanosized cubic $\mathrm{Y}_{2} \mathrm{O}_{3}: \mathrm{Eu}^{3+18}$ which makes this phosphor not particularly attractive for industrial applications. The energy efficiency of the CL between 380 and $780 \mathrm{~nm}$ of monoclinic $\mathrm{Y}_{2} \mathrm{O}_{3}: \mathrm{Eu}^{3+}$ at $15 \mathrm{kV}$ is found to be $0.2 \%$, which 20 times smaller than that of cubic $\mathrm{Y}_{2} \mathrm{O}_{3}: \mathrm{Eu}^{3+} \cdot{ }^{18}$ Curve 2 in Fig. 10 underpins the information presented in Fig. 7 that the total light output increases as the structure transforms from the monoclinic through a mixed monoclinic/cubic phase with increasing temperature treatment and finally to a pure cubic phase.

In Fig. 11 the CL and laser-activated spectra of undoped and doped monoclinic $\mathrm{Y}_{2} \mathrm{O}_{3}$ nanometre-sized particles are presented. The laser-activated spectrum of the undoped material in Fig. 11a shows surprisingly a strong luminescence signal at the anti-Stokes side $(543 \mathrm{~nm})$ of the He-Ne laser and at the Stokes side $(756 \mathrm{~nm})$ we detected also a rather strong luminescence. These two luminescence clusters are assigned to $\mathrm{Dy}^{3+}$, which was a contaminant of the $\mathrm{Y}_{2} \mathrm{O}_{3}$ starting material for the high-temperature plasma synthesis, present in the ppm-range. As mentioned above, this contamination could not be detected with our EDX equipment. The CL spectrum in Fig. 11a shows $\mathrm{Dy}^{3+}$ transitions at $573 \mathrm{~nm}$ and $485 \mathrm{~nm}$. The $\mathrm{Dy}^{3+}$ transitions will be discussed hereafter; first we shall concentrate on the laser-activated spectrum of $\mathrm{Eu}^{3+}$. Since the laser-activated spectra have been recorded with a high resolution Horiba Jobin Yvon Labram spectrometer, we shall represent some details of the spectra shown in Fig. 11b at larger abscissas in Fig. 12.
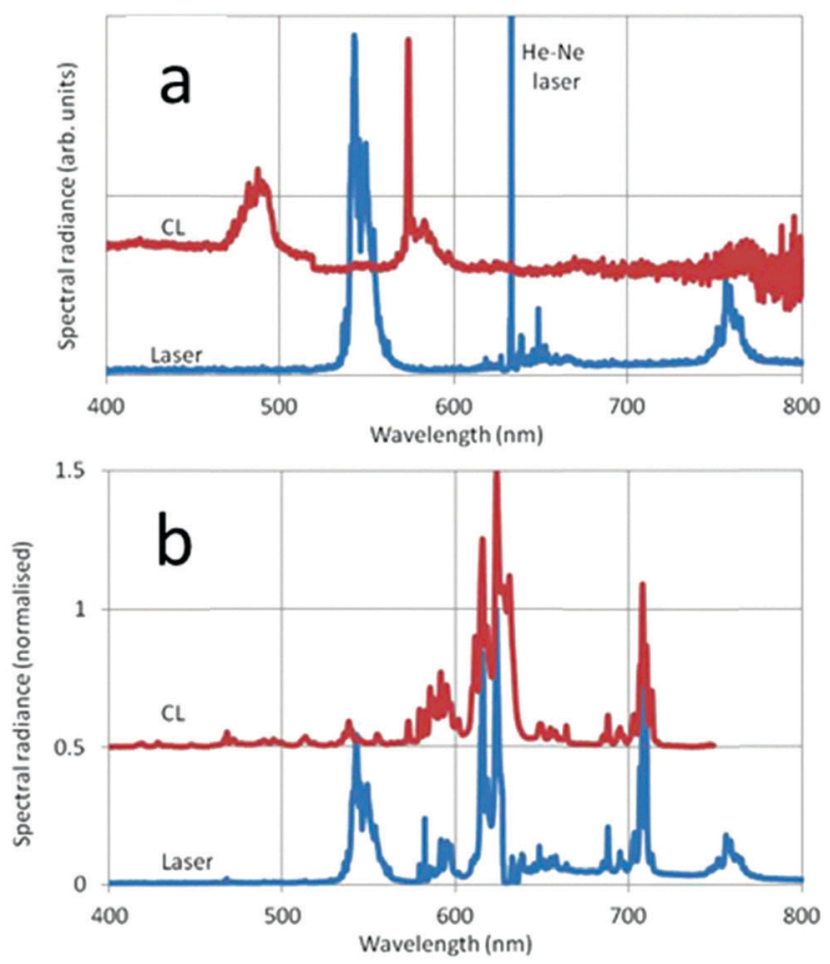

Fig. $11 \mathrm{CL}$ and laser-activated spectra of undoped monoclinic $\mathrm{Y}_{2} \mathrm{O}_{3}$ (a) and $\mathrm{Eu}^{3+}$ doped monoclinic $\mathrm{Y}_{2} \mathrm{O}_{3}$ (b). The $\mathrm{CL}$ spectra were recorded at $15 \mathrm{keV}$ beam energy and current density of $1 \mu \mathrm{A} \mathrm{cm}^{-2}$. The $\mathrm{He}-\mathrm{Ne}$ line in (b) has been deleted. 

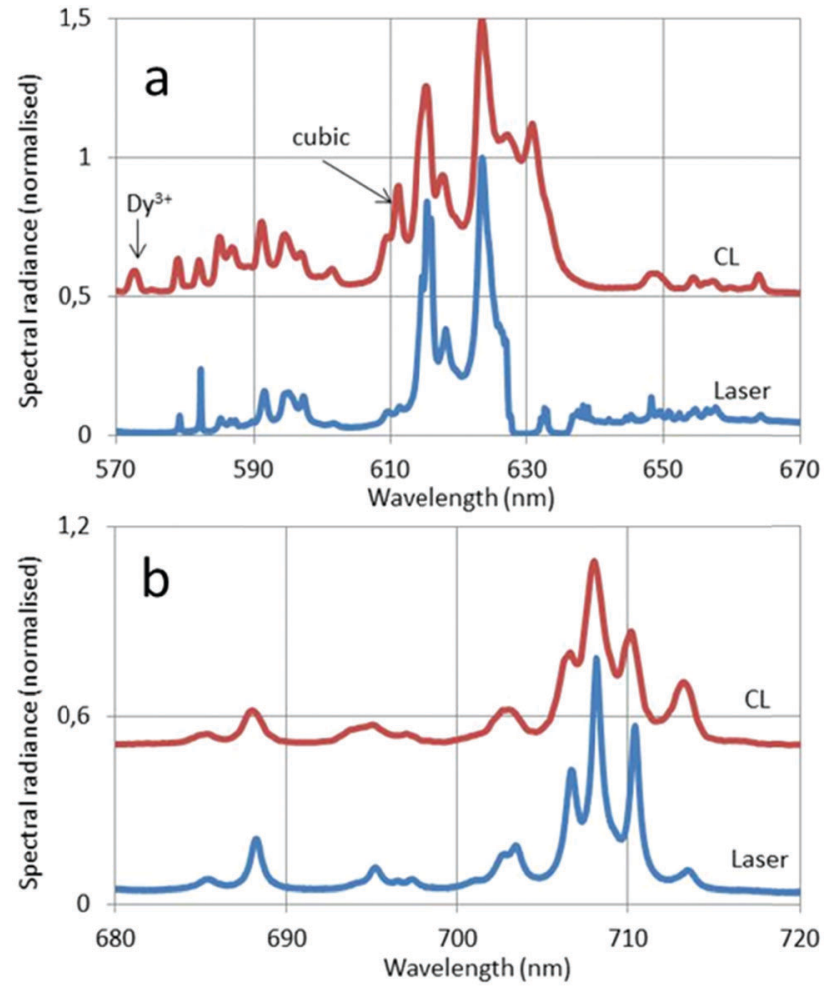

Fig. $12 \mathrm{CL}$ and laser-activated spectra of $\mathrm{Eu}^{3+}$ doped monoclinic. (a) From 570-670 nm; (b) from 680-720 nm. The CL spectra were recorded at $15 \mathrm{keV}$ beam energy and current density of $1 \mu \mathrm{Acm}^{-2}$. The $\mathrm{He}-\mathrm{Ne}$ line in (a) has been deleted. Normalisation has been made towards the ${ }^{5} D_{0} \rightarrow{ }^{7} F_{2}$ peak at $624 \mathrm{~nm}$

In Fig. 12a the ${ }^{5} \mathrm{D}_{0}{ }^{-}{ }^{7} \mathrm{~F}_{2}$ transition of the cubic phase at $611 \mathrm{~nm}$ has been indicated with an arrow. The spectral radiance of this transition is about four times smaller than the spectral radiance of the ${ }^{5} \mathrm{D}_{0}-{ }^{7} \mathrm{~F}_{2}$ transition of the monoclinic phase at $624 \mathrm{~nm}$. From this result we can estimate the amount of cubic phase in the sample doped with $\mathrm{Eu}^{3+}$.

Let $R_{611}$ (cubic) be the radiance of the ${ }^{5} \mathrm{D}_{0}-{ }^{7} \mathrm{~F}_{2}$ transition of the cubic phase and $R_{624}$ (mono) the radiance of the corresponding transition for the monoclinic phase, $x$ be the weight fraction of cubic phase, $\eta_{\mathrm{c}}$ and $\eta_{\mathrm{m}}$ be the energy efficiencies of the cubic and monoclinic materials respectively and $f_{\mathrm{c}}$ and $f_{\mathrm{m}}$ be the (fractional) contributions of the $611 \mathrm{~nm}$ and $624 \mathrm{~nm}$ transitions to the energy efficiency for the cubic and monoclinic materials respectively. From the low resolution spectra recorded with the Jeti radiometer we found that $f_{\mathrm{c}}=0.56$ and $f_{\mathrm{m}}=0.41$. This implies that the contribution of the ${ }^{5} \mathrm{D}_{0}{ }^{-} \mathrm{F}_{2}$ transition of the cubic phase to the energy efficiency is 1.36 times larger than that for the monoclinic phase. The fraction $x$ is calculated from the following equation

$$
\frac{R_{611}(\text { cubic })}{R_{624}(\text { mono })}=\frac{x \eta_{\mathrm{c}} f}{(1-x) \eta_{\mathrm{m}} f_{\mathrm{m}}} \approx 0.25
$$

Since $\eta_{\mathrm{c}}$ is 20 times larger than $\eta_{\mathrm{m}}$ we get $x \approx 0.9 \%$ : in other words, the yield of monoclinic phase by the plasma discharge synthesis is $>99 \%$ when we ignore the non-reacted $\mathrm{Y}_{2} \mathrm{O}_{3}$ precursor.

Both Fig. 8 and 12a show that only the CL spectrum of monoclinic $\mathrm{Y}_{2} \mathrm{O}_{3}: \mathrm{Eu}^{3+}$ exhibits clearly the ${ }^{5} \mathrm{D}_{0}{ }^{-}{ }^{7} \mathrm{~F}_{2}$ transition of the cubic phase at $611 \mathrm{~nm}$. This latter transition is much weaker in the PL and laser-activated spectra. The excitation mechanism for the latter two spectra is more subtle and depends strongly on the energy of the exciting radiation. Since we had no efficiency information for the PL and laser-activated spectra, we had to base our yield calculation on the CL-data only.

The ${ }^{5} \mathrm{D}_{0} \rightarrow{ }^{7} \mathrm{~F}_{2}$ peak at $615 \mathrm{~nm}$ in Fig. 8 and 9 is split in the laser-activated spectrum of Fig. 12a and consists of three peaks at $614.6 \mathrm{~nm}, 615.4 \mathrm{~nm}$ and $616 \mathrm{~nm}$. The laser-activated spectrum of nanosized cubic $\mathrm{Y}_{2} \mathrm{O}_{3}$ : $\mathrm{Eu}^{3+}$ was reported by Silver et al. ${ }^{24}$ They showed that besides Stokes and anti-Stokes luminescence, excitation of high-energy levels is possible through the absorption of two laser photons. This mechanism can also explain the presence of some (very) weak transitions in the laser-activated spectrum of monoclinic $\mathrm{Y}_{2} \mathrm{O}_{3}: \mathrm{Eu}^{3+}$ at $467 \mathrm{~nm}, 490 \mathrm{~nm}$ and $513 \mathrm{~nm}$, which belong to the ${ }^{5} \mathrm{D}_{2} \rightarrow{ }^{7} \mathrm{~F}_{J}$ manifold of $\mathrm{Eu}^{3+}$. In Fig. 12a we have indicated the $\mathrm{Dy}^{3+}$ transition in the CL spectrum at $573 \mathrm{~nm}$ with an arrow.

We shall now discuss the $\mathrm{Dy}^{3+}$ peaks in the laser-activated and CL spectra of Fig. 11a and b. The anti-Stokes cluster at $543 \mathrm{~nm}$ $\left(18412 \mathrm{~cm}^{-1}\right)$ is attributed to the ${ }^{4} \mathrm{I}_{15 / 2} \rightarrow{ }^{6} \mathrm{H}_{13 / 2}$ electronic transition of $\mathrm{Dy}^{3+}$, while the Stokes cluster at $756 \mathrm{~nm}\left(13224 \mathrm{~cm}^{-1}\right)$ is due to ${ }^{4} \mathrm{~F}_{9 / 2} \rightarrow{ }^{6} \mathrm{H}_{9 / 2}$. These transitions have been visualized in Fig. 13 by the green and red downward arrows respectively.

The assignments reported here are based on the electronic levels of $\mathrm{Dy}^{3+}$ in cubic $\mathrm{Y}_{2} \mathrm{O}_{3},{ }^{25}$ which deviate slightly from the values measured by us in monoclinic $\mathrm{Y}_{2} \mathrm{O}_{3}$. Only the lowest levels of the manifolds have been represented in Fig. 13. The excitation to the ${ }^{4} \mathrm{I}_{15 / 2}$ and ${ }^{4} \mathrm{~F}_{9 / 2}$ levels of $\mathrm{Dy}^{3+}$ is supposed to be controlled by the excited states absorption (ESA) process, as explained by Silver et al. ${ }^{24}$ First the ${ }^{6} \mathrm{~F}_{1 / 2}$ level is populated by the He-Ne laser. The energy trickles radiationless down to the

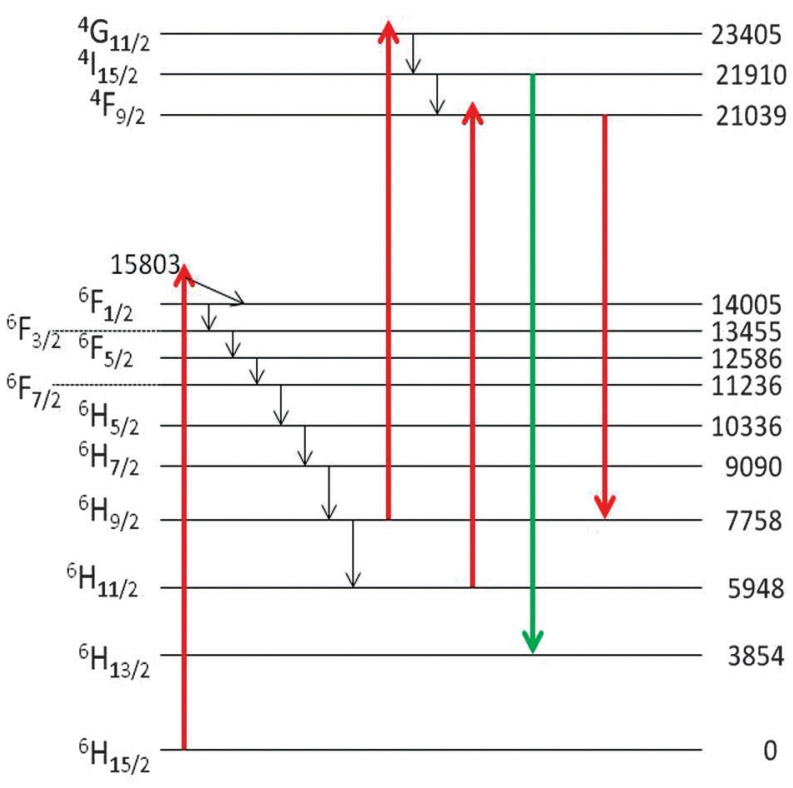

Fig. 13 Schematic energy level diagram of cubic $\mathrm{Y}_{2} \mathrm{O}_{3}: \mathrm{Dy}^{3+}$ and the proposed excitation and emission transitions. The energy levels, indicated in $\mathrm{cm}^{-1}$, are from Chang et al. ${ }^{25}$ 
${ }^{6} \mathrm{H}_{9 / 2}$ and ${ }^{6} \mathrm{H}_{11 / 2}$ levels, from where it can be excited to either the ${ }^{4} F_{9 / 2}$ or the ${ }^{4} G_{11 / 2}$ level by absorption of another He-Ne photon. We consider this ESA process more likely than an alternative route via the absorption of two He-Ne photons. The reason is that (1) a two-photon absorption would probably lead to very weak luminescence of $\mathrm{Dy}^{3+}$ and (2) the ESA process requires excitation of the ${ }^{6} \mathrm{~F}_{1 / 2}$ state, which is almost resonant with the He-Ne laser: it should be kept in mind that only the lowest level of the electronic states are indicated in Fig. 13. We have checked this hypothesis by using a laser at $532 \mathrm{~nm}$. When activating the undoped monoclinic $\mathrm{Y}_{2} \mathrm{O}_{3}$ with this laser we did not observe the characteristic transitions at $543 \mathrm{~nm}$ and $756 \mathrm{~nm}$ (not shown here). Hence, it can be concluded that the mechanism indicated in Fig. 13 for the luminescence of the monoclinic $\mathrm{Y}_{2} \mathrm{O}_{3}: \mathrm{Dy}^{3+}$ is likely.

The CL spectrum of Fig. 11a shows different $\mathrm{Dy}^{3+}$ transitions. The peak at $573 \mathrm{~nm}\left(17428 \mathrm{~cm}^{-1}\right)$ is due to ${ }^{4} \mathrm{~F}_{9 / 2} \rightarrow{ }^{6} \mathrm{H}_{13 / 2}$, while the cluster at $482 \mathrm{~nm}\left(20756 \mathrm{~cm}^{-1}\right)$ is attributed to ${ }^{4} \mathrm{~F}_{9 / 2} \rightarrow{ }^{6} \mathrm{H}_{15 / 2}$. These latter transitions were also recorded by Vetrone et al. ${ }^{26}$ in cubic $\mathrm{Y}_{2} \mathrm{O}_{3}: \mathrm{Dy}^{3+}$ with $\mathrm{PL}$. The differences between the $\mathrm{Dy}^{3+}$ levels of cubic and monoclinic $\mathrm{Y}_{2} \mathrm{O}_{3}$ : $\mathrm{Dy}^{3+}$ are rather small: the energy values indicated in the diagram of Fig. 13 refer to the lowest values of the manifolds and represent the right-hand sides of the recorded transitions clusters. The $\mathrm{Dy}^{3+}$ peak at $573 \mathrm{~nm}$ has been erased in the CL spectrum represented in Fig. 8 in order to avoid confusion, whereas it still present in the CL spectrum of the monoclinic material in Fig. 9.

In Fig. 14 we have depicted the Raman spectrum of undoped monoclinic $\mathrm{Y}_{2} \mathrm{O}_{3}$. In this figure spectrum (1) is the conventional Raman spectrum at the Stokes-side of the He-Ne line. Spectrum (2) has been derived from (1) by multiplication with the Boltzmann factor: $\mathrm{e}^{-h \nu / k T}$, in which $h$ is Planck's constant, $\nu$ is the frequency of the actual Raman line, $k$ is Boltzmann's constant and $T$ is $298 \mathrm{~K}$. Spectrum 3 in Fig. 14 is the anti-Stokes Raman spectrum. As expected, the spectra (2) and (3) are largely identical; nevertheless, spectrum (2) and the anti-Stokes spectrum (3) differ substantially at $\nu<150 \mathrm{~cm}^{-1}$ : the Raman peaks at $96 \mathrm{~cm}^{-1}, 106 \mathrm{~cm}^{-1}$ and $115 \mathrm{~cm}^{-1}$ are not observed in the anti-Stokes spectrum. The reason for this difference is unknown.

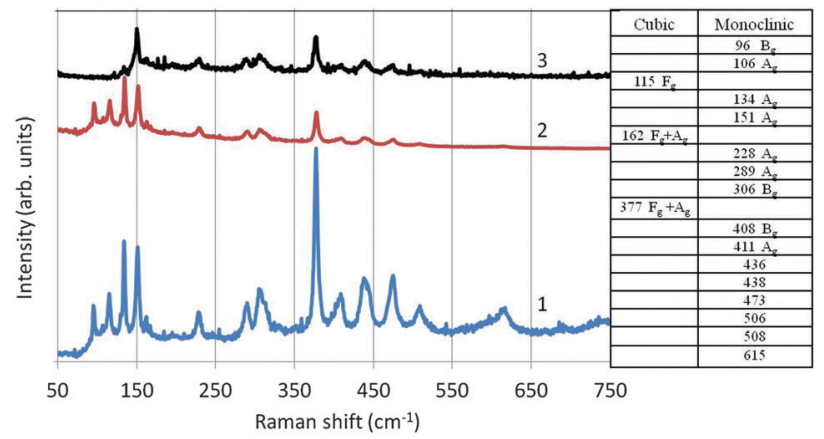

Fig. 14 Raman spectrum of undoped monoclinic $\mathrm{Y}_{2} \mathrm{O}_{3}$ (1). Spectrum (2) is derived from (1) by multiplying with the Boltzmann factor. Spectrum (3) is the anti-Stokes Raman spectrum. The table (values in $\mathrm{cm}^{-1}$ ) represents an incomplete assignment of the recorded Raman spectrum (1) of $\mathrm{Y}_{2} \mathrm{O}_{3}$.
In Fig. 14 we have also represented a table with an assignment of the Raman lines at $\nu<411 \mathrm{~cm}^{-1}$. As mentioned above, the high-temperature plasma synthesis of $\mathrm{Y}_{2} \mathrm{O}_{3}$ did not yield pure monoclinic material, but also some cubic crystals. Raman lines for cubic $\mathrm{Y}_{2} \mathrm{O}_{3}: \mathrm{Eu}^{3+}$ are at $115 \mathrm{~cm}^{-1}, 162 \mathrm{~cm}^{-1}$ and $377 \mathrm{~cm}^{-1}$, as indicated by Withnall et al. ${ }^{27}$ The other Raman lines of cubic $\mathrm{Y}_{2} \mathrm{O}_{3}: \mathrm{Eu}^{3+}$ detected by Withnall et al. were too weak to be observed in our sample with only about $15 \%$ cubic material. The assignment of the monoclinic Raman lines is based on the interpretation of the Raman spectra of monoclinic $\mathrm{Sm}_{2} \mathrm{O}_{3}, \mathrm{Eu}_{2} \mathrm{O}_{3}$ and $\mathrm{Gd}_{2} \mathrm{O}_{3}$ by Gouteron et $a$. $^{28}$

\section{Conclusions}

The main conclusions of this investigation of monoclinic $\mathrm{Y}_{2} \mathrm{O}_{3}$ and $\mathrm{Y}_{2} \mathrm{O}_{3}: \mathrm{Eu}^{3+}$ by XRD, TEM and spectroscopy are: (1) the yield of monoclinic phase by plasma discharge synthesis is more than $99 \%$ if we ignore the non-reacted $\mathrm{Y}_{2} \mathrm{O}_{3}$ precursor and (2) nanometresized monoclinic material is stable during shelf life at ambient conditions. We attribute this stability to the small particle size (between 5 and $50 \mathrm{~nm}$ ) of the monoclinic materials. We found that the luminous efficiency of monoclinic $\mathrm{Y}_{2} \mathrm{O}_{3}: \mathrm{Eu}^{3+}$ upon electron excitation is about 25 times less than that of the cubic material and we observed the transition from the monoclinic phase to the cubic phase at about $900{ }^{\circ} \mathrm{C}$ by XRD and PL. Since the starting $\mathrm{Y}_{2} \mathrm{O}_{3}$ material for the high-temperature plasma synthesis of monoclinic $\mathrm{Y}_{2} \mathrm{O}_{3}$ was contaminated with a small quantity of $\mathrm{Dy}^{3+}$, we were able to measure and interpret the laser-activated spectrum of monoclinic $\mathrm{Y}_{2} \mathrm{O}_{3}$ : Dy ${ }^{3+}$. Hence, this study has also shown that excitation of inorganic crystals with a He-Ne laser provides an extremely sensitive and specific measuring method for the spectroscopic determination of traces of $\mathrm{Dy}^{3+}$.

\section{Acknowledgements}

We are grateful to the EPSRC and the Technology Strategy Board (TSB) for funding the PURPOSE (TP11/MFE/6/I/AA129F; EPSRC TS/G000271/1), CONVERTED (JeS no. TS/1003053/1) and PRISM (EP/N508974/1) programs. We are also grateful to the TSB for funding the CONVERT program.

\section{References}

1 K. Kohmoto, in Phosphor Handbook, ed. W. Yen, S. Shionoya and H. Yamamoto, CRC Press, Boca Raton, 2nd edn, 2007, p. 437.

2 T. Justel, H. Nikol and C. Ronda, Angew. Chem., Int. Ed., 1998, 37, 3085.

3 J. Silver, Metal Compounds as Phosphors, in Comprehensive Coordination Chemistry II: The Synthesis, Reactions Properties and Applications of Coordination Compounds, ed. J. A. McCleverty, Pergamon Press, New York, 2003, ch. 9.15, vol. 9, p. 689.

4 P. Zhang, A. Navrotsky, B. Gao, I. Kennedy, A. N. Clark, C. Lesher and Q. Liu, J. Phys. Chem. C, 2008, 112, 932.

5 H. R. Hoekstra and K. A. Gingerich, Science, 1964, 146, 1163. 
6 A. Camenzind, R. Strobel and S. E. Pratsinis, Chem. Phys. Lett., 2005, 415, 193.

7 X. Qin, Y. Ju, S. Bernhard and N. Yao, J. Mater. Res., 2005, 20, 2960.

8 Y. C. Kang, D. J. Seo, S. B. Park and H. D. Park, Jpn. J. Appl. Phys., 2001, 40, 4083.

9 H. Chang, I. W. Lenggoro, K. Okuyama and T. O. Kim, Jpn. J. Appl. Phys., 2004, 43, 3535.

10 M. Okumura, M. Tamatani, A. K. Albessard and N. Matsuda, Jpn. J. Appl. Phys., 1997, 36, 6411.

11 W. Kraus and R. Birringer, Nanostruct. Mater., 1997, 9, 109.

12 D. K. Williams, B. Bihari, B. M. Tissue and J. M. McHale, J. Phys. Chem. B, 1998, 102, 916.

13 L. Wang, Y. Pan, Y. Ding, W. Yang, W. L. Mao, S. V. Sinogeikin, Y. Meng, G. Shen and H. K. Mao, Appl. Phys. Lett., 2009, 94, 061921.

14 J. Zhang, H. Cui, P. Zhu, C. Ma, X. Wu, H. Zhu, Y. Ma and Q. Cui, J. Appl. Phys., 2014, 115, 023502.

15 V. Gourlaouen, G. Schnedecker, A. M. Lejus, M. Boncoeur and R. Collongues, Mater. Res. Bull., 1993, 28, 415.

16 G. Kaptay, J. Nanosci. Nanotechnol., 2011, 12, 1.

17 D. R. Johnson, US Pat., US2014/0370293 A1, 2014.

18 D. den Engelsen, P. G. Harris, T. G. Ireland and J. Silver, ECS J. Solid State Sci. Technol., 2014, 3, R53.
19 X. Jing, T. Ireland, C. Gibbons, D. J. Barber, J. Silver, A. Vecht, G. Fern, P. Trogwa and D. C. Morton, J. Electrochem. Soc., 1999, 146, 4654.

20 D. den Engelsen, P. G. Harris, T. G. Ireland, R. Withnall and J. Silver, ECS J. Solid State Sci. Technol., 2013, 2, R201.

21 D. den Engelsen, G. R. Fern, T. G. Ireland, P. G. Harris, P. R. Hobson, A. Lipman, R. Dhillon, P. Marsh and J. Silver, J. Mater. Chem. C, 2016, 4, 7026.

22 J. Wen, L. Hu, M. Yin and S. Xia, Curr. Appl. Phys., 2012, 12, 732 .

23 J. B. Gruber, R. P. Leavitt, C. A. Morrison and N. C. Chang, J. Chem. Phys., 1985, 82, 5373.

24 J. Silver, M. I. Martinez-Rubio, T. G. Ireland, G. R. Fern and R. Withnall, J. Phys. Chem. B, 2001, 105, 9107.

25 N. C. Chang, J. B. Gruber, R. P. Leavitt and C. A. Morrison, J. Chem. Phys., 1982, 76, 3877.

26 F. Vetrone, J.-C. Boyer, J. A. Capobianco, A. Speghini and M. Bettinelli, Nanotechnology, 2004, 15, 75.

27 R. Withnall, J. Silver and T. G. Ireland, Proceedings of the XXIst International Conference on Raman Spectroscopy, 650 (2008).

28 J. Gouteron, D. Michel, A. M. Lejus and J. Zarembowitch, J. Solid State Chem., 1981, 38, 288. 